\title{
Rectal Adenocarcinoma
}

National Cancer Institute

\section{Source}

National Cancer Institute. Rectal Adenocarcinoma. NCI Thesaurus. Code C9383.

An adenocarcinoma arising from the rectum. It is more frequently seen in populations with a Western type diet and in patients with a history of chronic inflammatory bowel disease. Signs and symptoms include intestinal bleeding, anemia, and change in bowel habits. According to the degree of cellular differentiation, rectal adenocarcinomas are divided into well, moderately, and poorly differentiated. Histologic variants include mucinous adenocarcinoma, signet ring cell carcinoma, medullary carcinoma, serrated adenocarcinoma, cribriform comedo-type adenocarcinoma, and micropapillary adenocarcinoma. 